\title{
A Revolutionizing Supply-Chain Management
}

\author{
Donia Damak ${ }^{1}$ \\ ${ }^{1}$ Business Management Department, Donghua Unversity, Shanghai, China \\ Correspondence: Donia Damak, Business Management Department, Donghua Unversity, Shanghai, China. \\ E-mail: damak.donia@yahoo.fr
}

Received: January 22, 2018

doi:10.5539/ibr.v11n4p84
Accepted: February 11, 2018

Online Published: March 1, 2018

URL: https://doi.org/10.5539/ibr.v11n4p84

\begin{abstract}
Electronic commerce (EC) is possibly the most promising application of information technology witnessed in recent years. It is revolutionizing supply-chain management and has enormous potential for manufacturing, retail and service operations. E-commerce markets are growing at noticeable rates. The online market is expected to grow by 56\% in 2015-2020. This paper shows the importance of E-commerce and define it and examines its major elements that link organizational systems. The application of EC in manufacturing, retailing and service operations is examined, and a framework for describing EC components and their role in different areas of an organization is proposed. The first part of the paper discusses challenges and new trends in supply chain business intelligence and provides background research of big data initiatives related to EC. The rest of this paper is from a discussion of the e-commerce impact on supply chain management and the advantages of supply chain management of e-commerce platform. The trend of e-commerce platform is proposed based on the development supply chain management. What will be the effect of the Internet on supply chain? What is the relationship between e-commerce and supply chain management?
\end{abstract}

Keywords: e-commerce, implications, operations management, SCM

\section{Introduction}

Electronic commerce (EC) is a popular topic in the mass media and in informatics circles as well.

Perhaps its impact is most visible in the areas of financial services and retailing. Many EC initiatives have risen in a short period of time. Those initiatives include innovative smart cards to facilitate EC, remote payments and electronic checking online trading of stocks, bonds and related financial instruments, online banking, and online retailing (e-tailing). We are now becoming comfortable with the Internet, and we are beginning to appreciate its ability to provide a wealth of diverse information from around the globe; literally millions of sites are just a click away, opening up new opportunities for trade and information exchange.

Internet use is no longer a novelty; it is becoming as much a part of our daily lives as television and telephony. We have witnessed a true revolution with the growth of the Internet and Internet use, but now we are experiencing a second Internet revolution and it is called electronic commerce. The tools and techniques to enable trading over the Internet are becoming mature, and EC is growing very rapidly. (Asokan, Janson, Steiner, Waidner, 2002).

One can see evidence of EC everywhere on the World Wide Web (WWW). Many commercial web sites have catalogues and support online transactions, but EC is much more than these. It includes everything from sourcing to settlement and all the processes that underlie trading. The Internet's WWW has become the primary driver of contemporary EC.

Although the emphasis has moved from electronic data interchange (EDI) to the Internet, the focus is still on the technology required to exchange information rather than supporting inter- and intra-organizational business processes. EC is not just about facilitating individual business transactions, it also involves the management of the relationships that lead to and arise from transactions.

EC is the process of conducting business electronically among various entities in order to satisfy an organizational or individual objective. A key ingredient of EC, sometimes referred to as electronic trading, is the advertisement and procurement of goods and services over the Internet. The success and volume of EC on the web has been widely reported. With success in establishing an environment, in which EC can grow and flourish, 
every computer can become a window open to every business, large and small, around the globe.

The electronic medium we call the Internet has the potential to reduce actual transaction time and processing time dramatically, while at the same time making information available globally. Internet-based EC has been embraced as a means of reducing operational cost and as a high potential means of generating revenue. The ubiquity of the web and the availability of browsers across different platforms provide a common base upon which EC applications can be built, especially in the enterprise.

This common platform has reduced the significance of issues pertaining to software distribution and software installation, thus encouraging the expansion of EC via Intranets, Extranets and the Internet.

EC provides new channels for the global marketing of tangible goods and presents opportunities to create new businesses providing information and other knowledge-based intangible products. Although most EC is currently at the inter-corporate and inter-organizational level, services targeted at individual customers are evolving rapidly. The Internet is the most obvious example of this and is a major catalyst in the diffusion of EC, helping to foster a common environment for electronic transactions of all kinds (Morphett, 2001). EC encompasses all forms of interactive business transactions, which are facilitated by networks of computers.

EC is expanding because of the greater number of businesses and individuals who are able to use these networks and the growing number of ways in which businesses can conduct transactions electronically with other organizations and directly with consumers.

At present, business-to-business, EC seems still to be of greater volume than business-to-consumer EC, but this may change in the future. These trends are important to the global economy and to the economy of individual countries because EC contributes to economic efficiency.

EC contributes to economic efficiency in five important ways. They are as follows: (a) shrinking distances and timescale, (b) lowering distribution and transaction costs, (c) speeding product development, (d) providing more information to buyers and sellers and (e) enlarging customer choice and supplier reach (Levis, 2006).

The organization of this paper is as follows:

Section 2 presents the details and major elements of EC. Section 3 examines the application of EC in different areas of manufacturing, retailing, and service organizations. A framework describing the impact of EC on operations is proposed in Section 4. Finally, Section 5 presents a summary of findings and conclusions.

\section{Definition of and Major Elements of E-commerce}

$\mathrm{EC}$ is an emerging area that encompasses processes directly and indirectly related to the buying, selling and trading of products, services and information via computer networks - including the Internet. (Kalakota and Whinston, 2007) define EC from these four perspectives:

(a) Communication perspective - EC is the deliverer of information, products/services or payments over telephone lines, computer networks or any other electronic means, (b) business process perspective - EC is the application of technology towards the automation of business transactions and work flows, (c) service perspective - EC is a tool that addresses the desire of firms, consumers and management to cut service costs while improving the quality of goods and increasing the speed of service delivery and (d) online perspective EC provides the capacity to buy and sell products and information as well as other online services.

It is obvious that EC can be described in many ways. Perhaps the most useful description of EC would link it to trading: EC is trading by means of new communications technology. It includes all aspects of trading; including commercial market creation, ordering, supply chain management and the transfer of money. EC is actually a generic title that describes a range of technologies and practices that are now available to improve the effectiveness of trading relationships. At the application level, typical technologies would include: telephone, fax, EDI, electronic mail, electronic funds transfer, and the Internet - more specifically the Web. (Wakid, Barkley, Skall, 2010)

\subsection{Electronic Mail (E-Mail)}

E-mail is the exchange of computer-created and computer stored messages via a telecommunication network. E-mail was one of the first uses of the Internet and is still the most popular Internet use - a large percentage of Internet traffic is e-mail. E-mail can also be exchanged between online service users in private or public networks besides the Internet. The term e-mail is used almost interchangeably with messaging, however, it really represents only one aspect of messaging -interpersonal messaging (IPM), which is the exchange of text messages and attachments among individuals. E-mail is well established as a fast, flexible and cost-effective means of communication. It is simple to use. One need only complete a few steps to send, reply, and forward a 
message to one or many recipients, regardless of the geographic location. E-mail is linked to an electronic postal system wherein an addressed envelope accompanies each message sent to a mailbox.

From there, the message is dispatched to a delivery network, through which it is conveyed via the message transfer service until it arrives at the recipient's mailbox. Recipients then access their mailboxes and open their mail at a time that is convenient to them.

E-mail is a cheap and convenient way for people to communicate. As people spend more and more time away from a desk, it can be an easy and efficient way of exchanging information.

This can increase a person's productivity up to a point, beyond which e-mail volume can be so great that it inhibits productivity rather than enhancing it.

Under such conditions, groupware becomes a viable option to facilitate electronic interaction among groups of people who must communicate to accomplish group tasks. The greater control groupware can provide for the nature of participant communications and can encourage greater work related communications. Groupware products can be Internet based - NetMeeting is a good example of such a product.

\subsection{Electronic Data Interchange (EDI)}

Transacting regular business via e-mail has its limitations. Beyond a certain traffic volume, EDI becomes a preferred alternative. EDI is computer-to-computer exchange of business documents without human intervention. EDI can handle high volume transactional traffic between companies.

Formal document and transmission standards inherent in EDI, combined with adequate bandwidth, permit large transaction volumes. EDI enables enterprises to exchange precisely formatted business orders, payments, or even engineering drawings, electronically via a direct communication link, with no human intervention.

The major benefit of this technology is realized when EDI is integrated into a company's EC system. According to (Mohsen, 2007), EDI will help to reduce inventories, foster JIT management, promote engineering interchange, and improve work scheduling. Companies that have success-fully implemented EDI have reported general benefits of expedited purchasing processes, reduced transaction cycle times, higher inventory turnovers, faster response times and overall improved service (Sohal. 2012) states that EDI provides quick order responses from suppliers and automatic ordering from customers.

\subsection{Internet and Electronic Commerce}

The open standards of the Internet ensure that large organizations can easily extend their trading communities, by increasing the efficiency of their business operations. In addition, smaller companies Found the proprietary communication technologies of the last decade too complex and costly, can now select the level of communication appropriate for their businesses and benefit from the Internet revolution and the EC revolution. Organizations new to EC will find the open standards provided by Internet technologies easy to implement, quick to learn, and fast and efficient to use. The capabilities and opportunities afforded by an Internet-based electronic marketplace will significantly improve the productivity and competitiveness of participating companies, whether they are suppliers or customers.

The Internet houses an on-line global marketplace that operates 24 hours a day, with millions of sellers, buyers, products and services. The Internet and its capabilities also provide companies with new, more cost effective and time-efficient means for working with customers, suppliers and development partners. Internet-based EC will enable companies to:

- Shorten procurement cycles through the use of on-line catalogues, ordering, and payment;

- Cut costs on both stock and manufactured parts through competitive bidding;

- Reduce development cycles and accelerate time- to-market through collaborative engineering, product, and process design, regardless of the location of participants;

- Gain access to worldwide markets at a fraction of traditional costs;

- Ensure that the product, marketing information, and prices are always up to date;

- Significantly increase the speed of communication, especially international communication;

- Drastically reduce purchasing and production cycles;

- Reduce the cost of communications directly (E-mail and EDI save on postage) and speed up communication can reduce inventory and related inventory and purchasing costs; 
- Promote closer relationship with customers and suppliers, e.g. web sites enable companies to maintain customers and suppliers apprised of developments that concern them and practice effective relationship marketing;

- Provide a quick and easy way of exchanging information about a company and its products, internally and externally e.g. WWW sites, Intranets, and extranets;

- Take advantage of alternative sales channels and tap new markets or markets niches.

The Internet and WWW offer the opportunity to expand EC activity in the contract cycle to enable new suppliers to service new customers electronically, even to the point of negotiating new contracts. The WWW enables business-to-business and business-to-consumer transactions. Tim Berners-Lee created the web protocols in 1990 that were introduced onto the Internet in 1991 using Nicola Pellow's line-model browser and the existing hypertext mark-up language (HTML) (Aaron, Decina, Skillen 2012).

When combined with Mosaic in 1993, the web protocols brought us the world wide web (WWW of just the Web). The Internet, or more specifically the Web, is a key ingredient in EC, as we know it today. Among other things, the web provides a common platform for home pages and hence electronic storefronts, malls, auctions and more.

The success of the Internet and the popularity of the Web's user friendly, graphical user interface led to the development of Intranets (intra-organizational systems) and Extranets (inter-organizational systems). Intranets and Extranets rely on Internet protocols and Web interfaces.

These developments, along with the Internet, contributed to the growth of global procurement of goods and services. Probably more important is that the Internet-like technology infrastructures facilitated internal and external dissemination of company information and allowed firms to better manage customer relationships. Cisco Systems, with EC sales of over \$28 million per day, has been very successful in using Intranets and Extranets in support of its business processes. Cisco started with EDI, but migrated to a very sophisticated and highly effective customer management system.

\section{Application of E-Commerce in Operations (Manufacturing and Services)}

EC is changing manufacturing systems from mass production to demand-driven, possibly customized, just-in-time manufacturing systems.

Companies like IBM, General Motors, General Electric and Boeing are assembling products for which the components are manufactured in many locations. Sub-assemblers gather materials and parts from their vendors and they may use one or more tiers of manufacturers. Communication, collaboration and coordination become critical in such multitier systems. Using electronic bidding, assemblers get sub-assemblies 15-20 percent cheaper than before, and up to 80 percent faster.

These systems are flexible and adaptable, allowing fast changes with minimum cost. Costly inventories, once inherent in mass production systems, can be minimized (Turban, Lee, King, Chung, 2012)

Companies in the service sector, such as banks and stock brokerage houses, were online even before the Internet - the digitization of their business processes made this possible. In the early years of digitization in the financial industry, businesses such as banks provided clients with software on disc. The software that the users installed in their computers provided them with access to the vendor's database over private lines, and later over the Internet. Over time, companies started allowing customers to download the software instead of supplying it to them on disc.

Today, there is no need for the software since Internet browsers allow users to conduct business transactions with these service operations. Similarly, travel and real estate agents extracted information from information systems installed in their offices. They delivered information to the customers by mail and courier, or customers had to visit the agency office to get information and documentation of service transactions. For real estate businesses, customers visited the office to view a video clip or to see photos of real estate for sale. Today, many of the services of travel and real estate companies are available anywhere and anytime over the Internet. EC, largely through the Internet, provides customers with direct access to services. As a consequence, most of the value added tasks of agents and brokers can be automated. As more and more people accept EC as an alternative to more traditional labor intensive processes that have for years supported these types of service businesses, there will be less need for human representatives to directly provide the service and greater need for technical personnel to create and maintain the technical systems that support the services. The attention now is to how EC supports functional activities in organizations. 


\subsection{Marketing}

A market is a network of interactions and relationships where information, products, services and payments are exchanged. When the marketplace is electronic, the business center is no a physical building but rather a network that facilitates and supports business interactions and transactions. The electronic market brings buyers and sellers together, but not necessarily in the same place and not necessarily at the same point in time. The market handles all the necessary transactions to facilitate exchange, including the exchange of funds (with or without the involvement of banks). The advent of EC is changing marketing practice. In particular, the transformation of traditional intermediaries such as retailers occurs as a result of new computer-mediated relationships. One need only examine the setting of an interactive home-shopping supermarket to appreciate the changing role of the retailer in EC (Davis, Buchanan, Brodie, 2012). EC systems for business-to-business commerce on the Internet are still in their infancy.

Internet electronic markets for business-to-business $\mathrm{EC}$, follow the $\mathrm{n}$-suppliers while m-customers scenario is slowly evolving. Comprehensive Internet EC systems should provide sure and easy access, be easy to use, help overcome differences in time of business, location, and language between suppliers and customers, and at the same time support the entire trading process in business-to-business commerce. (Block and Segev, 2012) suggest the following EC impacts on marketing:

- Product promotion: EC enhances the promotion of products and services through direct, information-rich and interactive contact with customers.

- New sales channels: EC creates a new distribution channel for existing products, owing to its direct support of research on customers and the bidirectional nature of communication.

- Direct savings: The cost of delivering information to customers over the Internet results in substantial savings to senders (when compared with non-electronic delivery or delivery via VAN systems). Major savings are also realized in the direct delivery of digitized products (such as music and software) as compared to the costs of traditional delivery.

- Reduced cycle time: The delivery time for digitized products and services can be reduced to seconds. Also, the administrative work related to physical delivery, especially across international borders, can be reduced significantly, reducing the cycle time by more than 90 percent.

- Customer service: Customer service can be greatly enhanced by enabling customers to find detailed information online. (For example, FedEx allows customers to trace the status of their packages.) Also, intelligent agents can answer standard e-mail questions in seconds.

Finally, human expert services can be expedited using help-desk software. EC supports marketing intelligence. Intelligence systems aid in acquiring information to evaluate alternatives and to assist in making choices (choice is selection from among the alternatives). EC directly supports the following three intelligence activities: (a) search for products, (b) management of search criteria, and (c) comparison of products found.

(a) Search for products: Once one feels/recognizes a need, one develops a set of more or less specific criteria for a desired product. One can then search for products that meet the criteria. In using the Internet for one's search, one might use hyperlinks, 3D navigation, a search engine or any other navigational technology to assist one in one's search. During this search one may decide to switch to criteria management or comparison activity. Such a switch might be promoted by on-screen information (e.g. an advertisement for a related product) or as the result of an internal decision (e.g. due to an impasse in the search for a particular product).

(b) Management of search criteria: Criteria management occurs when one encounters information that prompts one to alter one's search criteria. The alteration may be a slight refinement of the current criteria or the specification of completely new search criteria. Criteria may become more specific due to acquired information (i.e. in examining laptop computers and discovering great variation in weights, one might decide that the weight is an important consideration in the decision and set a specific target for the laptop weight). At times, an entirely new set of criteria will be generated, e.g. when a user encounters a product that fulfils other needs in addition to meeting current purchasing goals. This activity may occur before the search for products, as when the Web is used to gather information to supplement one's knowledge of the product one intends to purchase. In most cases, the search and specification of what is to be searched for will be the interleaved (but defined) activities. The decision to switch from a search goal to a criteria management goal will often be prompted by the 
display. Examples of prompts include advertisement, buttons offering product reviews, links to other information sources and the exposure to other products.

(c) Comparison of products: As users identify potential purchases, they need to compare them with each other, e.g. to find the cheapest, or perhaps the lightest. Often comparison will require simultaneous and relative assessment of products on a number of criteria. This stage corresponds to the Guttman, 2012 stages of product and merchant brokering.

\subsection{Purchasing}

Automated purchasing and logistics are carried out between trading partners with well-established relationships - this is a primary application of EDI. Intelligence and valuable information are normally concentrated on the computer systems of the participants rather than the EDI channel between them. The purchase and direct selling offers the prospect of large-scale disintermediation eliminating middlemen from supply chains. Some traditional intermediary roles will become threatened as businesses and individuals reevaluate their trading patterns in response to new EC opportunities; however, far from eliminating the need for intermediaries, the Internet is currently generating a wide range of new opportunities in the facilitation and mediation of electronic trading environments. On-line purchasing environments are still very much in their infancy, and over the next few years, one may expect to see a rapid increase in the functionality of these environments that will assist both buyers and sellers. Intelligent purchasing advisors will assist buyers in specifying their product requirements, searching for product in formation, and selecting the best supplier. This might lead to a shift in the balance of power from sellers to buyers.

Delivery of a product can signal the termination of the negotiation stage or occur sometime afterwards (in either order). In some cases, the available payment options or delivery options may influence product and merchant brokering.

\subsection{Design}

High quality design of products has been successfully achieved with the help of quality function deployment (QFD), design for manufacturing and design for quality. Also, various computer-based technologies have helped to improve the quality of product designs. These include computer-aided design (CAD), 3D Modeling and ProEngineer to reduce the time to develop new products. Since companies have been forced to compete based on flexibility and responsiveness in a global market, there is a need to reduce the product development cycle time it accounts for a major portion of the total lead-time to deliver the product after receiving orders from customers.

Concurrent engineering (CE) has been employed to improve the communication between design and other functional areas by using cross-functional, multi-disciplinary teams for new product development. CE requires input from customers as well as from within the organization. The Internet can power methods such as QFD, and web-based data collection and mining, to help improve the quality of design and to enhance competitiveness in global markets. Design engineers located in different parts of the country or world can exchange information using the Internet and WWW.

This can reduce design time and improve the accuracy of the information on product design, and at the same time help to design products that will capture good market share. Companies are using an approach for marketing that uses continuously refined information about current and potential customers to anticipate and respond to their needs.

This is the practice of customer relationship management (CRM). CRM software (run by Internet) can be utilized to conduct research on customer requirements to facilitate better product design.

\subsection{Production}

For organizations to stay in synchronization with the changes taking place in their operational and competitive environments, the use of fast, accurate information systems is crucial.

The implementation of e-manufacturing or e-service necessitates business-to-business (B2B) e-commerce. There are numerous Internet enabled supply chain management systems and enterprise resource planning (ERP) systems available today including MRP, SAP, BAAN, Oracle, and IBM e-business. Communication and data collection constraints are reduced with Web-based production of goods and services. Using database management, data warehouse and data mining technologies, the Web can facilitate interaction with customers and suppliers, data collection, and data analysis processes (Wang, Head, Archer 2012).

Outsourcing of service functions is becoming popular. By strategically outsourcing and focusing a company's core competencies, managers can leverage their firm's limited skills and resources for increased competitiveness. 
Venkataraman and Henderson 2013 asserted that three interdependent vectors, the virtual encounter, virtual sourcing, and virtual expertise, are integral in realizing a virtual organizational structure.

Outsourcing offers firms the option of securing many, if not all of the capabilities necessary to conduct business-to-business and business-to-consumer EC.

The commercial applications on the Internet and their integration, with internal information systems such as intranets and enterprise resource planning (ERP) systems, have resulted in significant changes in networking and other technologies available for interorganizational information systems (IOS), allowing other business functions to make use of these networks (Wang, Head, Archer 2012). More advanced IOS extensions that affect suppliercustomer relationships include Web-based interfaces, integration with supplier catalogues and internal information systems, and built-in business transaction rules based on purchase limits or negotiated contracts. Extremely close supplier-customer relationships, such as those between parts suppliers and automobile manufacturers, can encourage the use of IOS to link suppliers to customer inventory and production forecast data, transferring to suppliers the responsibility for automatic replenishment.

\subsection{Sales and Distribution}

EC looks like it is finally coming into the mainstream and retailers are beginning to realize its key role in customer service. A large number of potential web shoppers abort their transactions in frustration over the process and have security fears about web-based transactions. Powerful techniques have been developed in the Internet framework to support the security requirements that are the foundation of EC (e.g., integrity, authentication, authorization and non-repudiation). Also, EC models for business-to-business and consumer-to-business transactions have been developed.

Moreover, the necessary regulation framework is being settled [28]. Notwithstanding technological support, human contact is still an important aspect that makes shopping in the physical world more comfortable to most people than shopping online.

So far, many people who surf retail web sites for products or services end up completing the commercial transaction over the phone. Strategies and products for bringing better customer service to EC are beginning to emerge. Internet telephony may be the missing link in the web shopping process. In the increasingly crowded arena of online shops and full-fledged e-malls, Internet protocol (IP) calling may be a strong point of differentiation. If vendors can harness IP voice technology to create icons and connections for live contact and call-back customer assistance, it could vastly increase the efficiency and the value of existing retail web sites and provide a more solid business model for launching new EC ventures.

The future pattern of competition between businesses is being reshaped by a number of new technical systems that provide new channels through which to reach consumers, and which allow the entry of new competitors into the established, once difficult to penetrate markets.

Companies formerly engaged solely in manufacturing and selling to intermediaries, like large textile and apparel manufacturers, have recognized opportunities created by these new technologies to compete directly with large retailers. Manufacturers are faced with a continual squeeze on profit margins for branded goods as retailers increase their buying power through increased scale of operation (larger size). Wal-Mart's practice of "power buying" is a good example - Wal-Mart dictates the terms of exchange and manufacturers can "take it or leave it." Manufacturers face stiff competition from retailers who are increasingly emphasizing their own store brands, which quite often are produced in developing nations at a very low cost, forcing manufacturers to search for ways to compete more effectively and restore profitability. Information gained at the point of sale and control of display space allocation in stores, once gave retailers great advantage in increasing the market shares of their own brands (Graham, Hardaker, 2013). Additionally, retailers demanded high product variety from manufacturers, but it did not necessarily translate into display of the manufacturers full range of products within the retail establishments. Where there are conflicting views on marketability, only a limited number of products can gain shelf space.

For manufacturers, there are significant advantages to be gained from using new distribution channels to give visibility to their full range of products and to improve their competitive position by establishing close direct contact with those why buy their products. EC provides manufacturers with a great opportunity to sell and distribute directly to final customers.

One of the emerging EC technologies that some manufacturers have investigated is the smart Kiosk.

These are sophisticated devices spawned from the automated teller machine (ATM) systems used by banks. Touch screen driven terminals linked to distant servers use hypermedia systems to provide information on 
products and support credit card purchases. Kiosks are thought suitable for location in high access public sites such as entertainment complexes, fast food restaurants, airports and train stations [30]. Kiosks can be used in retail stores to widen the range of products that are offered and to provide additional product information. They might also provide a supplement to the development of Internet selling-providing access points for those who do not have Internet access.

Obviously, these systems, as with other alternatives to traditional in-store retailing, have to be supported by effective networks of manufacturing or warehouse locations that can rapidly deliver products to customers. In this, as with the broader changes in supply chain management, the role of logistics is increasingly critical to success - it is not enough to sell a product at a competitive price, one must get it to the consumer fast to be considered a viable alternative to traditional store retailers.

Alternative marketing channels such as the Internet, and interactive cable and satellite-based teleshopping, are currently believed to offer great promise in changing the landscape of modern retailing. During a transitional stage, the Internet was mainly used to provide product information and to project a specific company image via web pages, but the number of retailers and manufacturers selling via the Internet is increasing daily.

A number of virtual malls have been developed to provide display space for groups of retailers, including smaller companies. Use of the Internet for selling is partly dependent on confidence in the security of Internet transactions.

It is note worthy, therefore, that encryption techniques and related security technology have improved to the point that Internet transactions may actually be less risky than traditional face-to-face and telephone transactions. Faster Internet access made possible by better phone modems, cable modems, faster processors, increased RAM, and more, have like-wise played a role in the expansion of Internet based EC.

The Internet can actually be used to distribute many informational products, as well as products like software and music that can also be digitized. Internet distribution can produce significant savings in shipping, and it facilitates delivery at speeds only hoped for by those using other, more traditional delivery modes such as truck, air, and rail. Even those who use traditional modes of transportation can use Internet based tools to increase customer service.

Web-based order tracking has become commonplace. It allows customers to trace the shipment of their orders without having to contact the shipper directly. UPS was one of the pioneers in offering this web-based customer service.

\subsection{Human Resource Management}

The labor market has reached the web. One need only key in "jobs" in a search on nearly any search engine to discover the extent to which recruiters and job hunters have invaded the web.

Sites like Asia expact.com and job.com abound on the web. The web is now a good place for recruiters to go in search of employees, and for job hunters to go in search of jobs.

Many manufacturers, retailers, and service providers now advertise job openings on their own sites, making it easy for qualified applicants to contact them. Further-more, the data supplied by applicants can be directed to a database, making it very easy for the HRM personnel to limit their examination of applicant data, to only those meeting specific search criteria.

Some companies have made it possible for employees to manage their benefits and retirement accounts via the web. Employees can access information concerning their benefits or retirement accounts, and they can in many instances make changes themselves, without the assistance of a HRM representative.

This is convenient for employees and it is a time saver for HRM employees, who are relieved of some of the tasks related to supplying information to employees about benefits, retirement, policies, and more. One might not initially think of these things as EC, but they do fall within the domain of EC. Multimedia training and education is likewise possible with the Internet. Education and training can be purchased and delivered via the Internet, Extranets or Intranets. A major advantage of this approach is that those using the services can opt to use them at a convenient time, and at their own pace, unlike education and training provided through seminars, or the traditional classroom environment. Much of the education and training made available in this way is interactive in nature, which enhances its value to users by making it less boring and more effective.

\subsection{Warehousing}

EDI can help to minimize warehousing cost. EDI enables minimal stocks to be held with the resultant saving in the costs of storage, insurance, warehousing and security. Improved audit trails lead to better stock management 
and account- ability. Reduction in manual processing reduces the need for people, thus labor cost savings are possible. Just-in-time manufacturing refers to the ability to produce minimal sized batches of finished goods, only when needed, i.e. responding to market pull; in an extended supply chain, EDI leads to minimal stock holdings by all parties and hence a reduced supply chain system operating costs. EDI also helps to improve cash flow - vast improvements in matching invoices against orders and receipts become possible leading to timely payment. Reduced stock handling saves money (Davis, Buchanan, Brodie 2011).

\subsection{Supplier Development}

EC's access to information and suppliers can empower buyers by giving them access in turn to a larger number of alternative products, and by allowing them to consider a larger number of vendors. Companies can also establish contact and do business with a wider range of trading partners and customers. Many organizations can do business globally because EC can reduce and even eliminate barriers associated with time and distance (Levis. 2006) Intelligent agents can assist buyers in finding the best prices on products and the most favorable terms available from suppliers. These intelligent agents can do in seconds, or perhaps minutes, what might take a person days or weeks to do using traditional approaches to comparison shopping which require phone, catalogues, and lots of time.

Networks can also help businesses by communicating more often and more effectively with suppliers and customers, using a variety of media that provide for richer, more personalized communications. More information can be exchanged between internal and external entities, which previously had no contact with each other.

Businesses have shown tremendous interest in using the Internet as a means for building stronger relationships with customers, suppliers and business partners as well as in using Internet-based networks internally to facilitate collaboration between employees, dissemination of information, and reduction of communication expenses (Decina, Trecordi 2012).

\section{A Framework for Improving the Operations in an E-Commerce Environment}

As the ever-growing WWW becomes more popular, EC promises to become a mainstay of modern business (Griffith, Elson, Amos 2012). Enterprises are generating demand for Internet connectivity through the development of new service offerings that provide value to customers. Many people think EC is just having a web site, but EC is much more than that.

There are dozens of applications of EC such as home banking, shopping in online stores and malls, buying stocks, finding a job, conducting an auction and collaborating electronically on research and development projects (Aaron, Decina, Skillen, 2010). To execute these applications, it is necessary to have supporting information, and organizational infrastructure and systems. Companies now find that the development of a WWW presence is a competitive necessity, particularly for retailers who need to establish online storefronts. Even so, there are few useful frameworks in the EC literature to help managers understand the potential of EC.

The framework proposed herein relates E-commerce application areas and EC tools and systems to the various functional areas of an organization to suggest how EC might support functional activities (see Table 1). For example, marketing can use e-commerce tools and systems such as B2B systems, Internet ordering, and Web sites to promote products or services, develop sales channels, achieve direct cost savings, reduce cycle time, and enhance and expand customer services.

Similarly, production can apply the e-commerce systems such as B2B systems; Internet powered MRP, ERP, SAP and BAAN are applied for effective production, planning and control, scheduling, inventory management and quality control. WWW communication, e-mail, and research can assist in supplier development, data mining and data warehousing, for more productive models partnership formation and supplier development.

E-commerce technologies can be used in other functional areas such as purchasing, design, sales and distribution, human resource management and warehousing (see for further details, Table 1). 
Table 1. Application of e-commerce in operation

\begin{tabular}{|c|c|c|}
\hline Organizational functional areas & $\begin{array}{l}\text { E-commerce applications and/or } \\
\text { contributions }\end{array}$ & E-commerce tools and systems \\
\hline Marketing & $\begin{array}{l}\text { Product promotion, new sales channels, } \\
\text { direct savings, reduced cycle time, } \\
\text { customer services }\end{array}$ & $\begin{array}{l}\text { B2B e-commerce, Internet ordering, } \\
\text { Website for the company }\end{array}$ \\
\hline Purchasing & $\begin{array}{l}\text { Ordering, fund transfer, supplier } \\
\text { selection }\end{array}$ & EDI, Internet-purchasing, EFT \\
\hline Design & $\begin{array}{l}\text { Customer feedback, research on } \\
\text { customer requirements, product } \\
\text { design, quality function } \\
\text { deployment, data mining and } \\
\text { warehousing }\end{array}$ & $\begin{array}{l}\text { WWW integrated CAD, Hyperlinks, } \\
\text { 3D navigation, Internet for data and } \\
\text { information exchange }\end{array}$ \\
\hline Production & $\begin{array}{l}\text { Production planning and control, } \\
\text { scheduling, inventory management, } \\
\text { quality control }\end{array}$ & $\begin{array}{l}\text { B2B e-commerce, MRP, ERP, SAP, } \\
\text { BAAN, IBM e-commerce (web } \\
\text { integrated) }\end{array}$ \\
\hline Sales and distribution & $\begin{array}{l}\text { Internet sales, selection of distribution } \\
\text { channels, transportation, scheduling, } \\
\text { third party logistics }\end{array}$ & $\begin{array}{l}\text { Electronic funds transfer, On-line TPS, } \\
\text { Bar-coding system, ERP, WWW } \\
\text { integrated inventory management, } \\
\text { Internet delivery of products and } \\
\text { services }\end{array}$ \\
\hline Human resource management & $\begin{array}{l}\text { E-recruiting, benefit selection and } \\
\text { management, training and education } \\
\text { using WWW }\end{array}$ & $\begin{array}{l}\text { E-mails, interactive web sites, WWW } \\
\text { based multimedia applications }\end{array}$ \\
\hline Warehousing & $\begin{array}{l}\text { Inventory management, forecasting, } \\
\text { scheduling of work force }\end{array}$ & $\begin{array}{l}\text { EDI, EFT, WWW integrated inventory } \\
\text { management }\end{array}$ \\
\hline Supplier development & Partnership, supplier development & $\begin{array}{l}\text { WWW assisted supplier selection, } \\
\text { communication-using Internet } \\
\text { (e-mails), research on suppliers and } \\
\text { products with WWW and intelligent } \\
\text { agents }\end{array}$ \\
\hline
\end{tabular}

\section{Summary of Findings and Conclusions}

By examining the evolving role of e-commerce on the operation of manufacturers, retailers, and service providers. A framework for describing EC components and their role in operations is set forth. For companies that fully exploit its potential, EC offers the possibility of breakthrough changes; changes that so radically after customer expectations that they redefine the market or create entirely new markets.

To reap the benefits of EC, firms must understand its potential, its components, their own businesses, and the businesses of trading partners.

Businesses must focus on strong partnerships and the core products and structure that make EC possible. They must define, develop, and use the EC infrastructure that will empower their businesses to take advantage of new business opportunities. Development of effective strategies for achieving competitive advantage through EC will be necessary for success in the 21 st century.

EC requires substantial infrastructure planning. Pursuing EC goals with underpowered hardware equipped with inadequate bandwidth, ill-considered software, and no coherent data management strategy is a recipe for disaster.

Infrastructure planning is critical to success. A badly designed system performs poorly at best and at worst invites security problems. The infrastructure must be designed with sufficient flexibility to allow for adaptive change, as will be surely mandated with the continued evolution of EC.

Good infrastructure planning can make the difference in whether future EC developments create problems or opportunities for a business. Historically, many infrastructure services have been provided by subscription with direct monthly aggregated billing. EC enables other business models such as immediate payment for services. Rather than each provider providing separate user billing, a common shared billing infrastructure, similar to the 
credit card associations, could be developed. This may be more flexible and cost-effective and it may reduce credit risks to providers.

A necessary ingredient of EC, user authentication to prevent fraud, has a major disadvantage for users with the loss of privacy. Authentication allows providers to log user activities and data warehousing across a variety of suppliers and providers. Without definitive privacy policy, the development of a dynamic market may be stifled. A customer care organization can preserve user anonymity and enforce privacy policy.

The world around us is rapidly changing. The above-mentioned issues must be addressed, as must others that exists, or will arise. The Internet and other EC related developments have the potential to radically change the ways in which we communicate, interact, receive information and entertainment, and acquire goods and services. For businesses to survive and prosper in the $21^{\text {st }}$ century and beyond, they must develop business

\section{References}

Aaron, R., Decina, M., \& Skillen, R. (2009). Electronic commerce: Enablers and implications. IEEE Communications Magazine, 37(9), 47-52. https://doi.org/10.1109/35.790861

Archer, N., \& Yuan, Y. (2011). Managing business-to-business relationships throughout the e-commerce procurement life cycle. Internet Research: Electronic Networking Applications and Policy, 10(5), 385-395. https://doi.org/10.1108/10662240010349390

Asokan, N., Janson, P. A., Steiner, M., \& Waidner, M. (2002). The state of the art in electronic payment systems. IEEE Computer, 30(9), 28-35. https://doi.org/10.1109/2.612244

Bartell, R. L., Blackwood, N. A., Eggenschwiler, D., Nguyen, M., Schnidrig, C., \& Yatchman, M. J. (2012). The MediaXactt system - a framework for personalized electronic commerce services. Bell Labs Technical Journal, 4(2), 153-173. https://doi.org/10.1002/bltj.2170

Block, M., \& Segev, A. (2010). Leveraging electronic commerce for competitive advantage: A business value framework, Proceeding of the Ninth International Conference on EDI ISO, Bled, Slovenia, 2010.

Boll, S., Gruner, A., Haaf, A., \& Klas, W. (2014). EMP - A database driven electronic market place for business-to-business commerce on the Internet. Distributed and Parallel Databases, 7(2), 149-177. https://doi.org/10.1023/A:1008754511383

Boudette, N. (2010). Electronic data interchange. Industry Week, 18, 52-55.

Davis, R., Buchanan, O. M., \& Brodie, R. (2013). Relationship marketing in electronic commerce environments. Journal of Information Technology, 14(4), 319-331. https://doi.org/10.1080/026839699344449

Decina, M., \& Trecordi, V. (2013). Voice over Internet protocol and human-assisted e-commerce. IEEE Communication, 574-585.

Garrett, S. G. E., \& Skevington, P. J. (2012). An introduction to e-commerce. BT Technology Journal, 17(3), 11-16. https://doi.org/10.1023/A:1009612000420

GE, Building virtual global trading communities through electronic commerce outsourcing, White Paper, 2012.

Graham, G., \& Hardaker, G. (2012). Supply-chain management across the Internet. International Journal of Physical Distribution and Logistic Management, 30(3/4), 286-295. https://doi.org/10.1108/09600030010326055

Griffith, J., \& Elson, B. D. (2011). Amos, A customer-supplier interaction model to improve customer focus in turbulent markets. Managing Service Quality, 11(1), 57-66. https://doi.org/10.1108/09604520110366151

Guttman, R. H., Moukas, A. G., \& Maes, P. (2009). Agent-mediated electronic commerce: A survey. Knowledge Engineering Review, 13(2), 147-159. https://doi.org/10.1017/S0269888998002082

Kalakota, R., \& Whinston, A. B. (2012). Electronic Commerce: A Manager's Guide, Addison-Wesley, Reading, MA, 2012.

Levis, K. (2006). Electronic commerce. British Telecommunications Engineering, 14(4), 281-285.

Mohsen, A. (2012). CIM getting set for implementation. International Journal of Industrial Management and Data Systems, 97(1-2), 3-9.

Morphett, I. (2006). Foreword. BT Technology Journal, 17(3), 17-23.

OECD, Electronic Commerce: Opportunities and Challenges for Government, OECD Publication, Vienna, 2010.

Peppard, J. (2009). Customer relationship management (CRM) in financial services. European Management 
Journal, 18(3), 312-327. https://doi.org/10.1016/S0263-2373(00)00013-X

Sohal, A. S. (2012). Computerised parts traceability: An implementation case study. Technovation, 17(10), 583-591. https://doi.org/10.1016/S0166-4972(97)00039-4

St. John, C. H., Cannon, A. R., \& Pouder, R. W. (2010). Change drivers in the new millennium implications for manufacturing strategy research. Journal of Operations Management, 19, 143-160. https://doi.org/10.1016/S0272-6963(00)00054-1

Steward, S., \& Videlo, I. D. E. (2010). Intelligent on-line purchasing. British Telecommunications Engineering Journal, 17(1), 28-36.

Turban, E., Lee, J., King, D., \&. Chung, H. M. (2011). Electronic Commerce: A Managerial Perspective, Prentice-Hall International (UK) Limited, London, 2011.

VanderAalst, W. M. P. (2010). Process-oriented architectures for electronic commerce and interorganizational workflow. Information Systems, 24(8), 639-671. https://doi.org/10.1016/S0306-4379(00)00003-X

Venkatraman, N., \& Henderson, J. C. (2013). Real strategies for virtual organizing. Sloan Management Review, 40, 33-47.

Wakid, S., Barkley, J., \& Skall, M. (2010). Object retrieval and access management in electronic commerce. IEEE Communication Magazine, 37(9), 74-77. https://doi.org/10.1109/35.790905

Wang, F., Head, M., \& Archer, N. (2010). A relationship-building model for the Web retail marketplace. Internet Research, 10(5), 374-384. https://doi.org/10.1108/10662240010349381

\section{Copyrights}

Copyright for this article is retained by the author(s), with first publication rights granted to the journal.

This is an open-access article distributed under the terms and conditions of the Creative Commons Attribution license (http://creativecommons.org/licenses/by/4.0/). 